Can Creativity Beat Death? A Review and Evidence on the Existential Anxiety Buffering Functions of Creative Achievement

Running Head: Can Creativity Beat Death? 


\begin{abstract}
The relationship between creativity and symbolic immortality had been long acknowledged by scholars. In a review of the literature, we found 12 papers that empirically examined the relationship between creativity and mortality awareness using a TMT paradigm, overall supporting the notion that creativity plays an important role in the management of existential concerns. Also, a mini meta-analysis of the impact of death awareness on creativity resulted in a small-medium weighted mean effect. We examined the existential anxiety buffering functions of creative achievement as assessed by the Creative Achievement Questionnaire in a sample of 108 students. It was found that at high, but not low, levels of creative goals, creative achievement was associated with lower death-thought accessibility under mortality salience in comparison to controls. To our knowledge, this is the first empirical report of the anxiety buffering functions of creative achievement among people for whom creativity constitutes a central part of their cultural worldview. The current findings support the notion that creative achievement may be an avenue for symbolic immortality, particularly among individuals who value creativity. Implications for understanding death-related creativity motivations and their impact on individuals and society and for the promotion of creative achievement and creative motivation are discussed.
\end{abstract}

Keywords: creativity, creative achievement, symbolic immortality, terror management theory, meta-analysis 
"When I'm gone you will remember my name

I'm gonna win my way to wealth and fame"

Bob Dylan

Creativity has been defined as "the achievement of something remarkable and new, something which transforms a field of endeavour in a significant way“ (Feldman, Csikszentmihalyi, \& Garderner, 1994, p.2). A sense of immortality has been referred to as representing one's desire to maintain "an inner sense of continuous symbolic relationship, over time and space, with the various elements of life" (Lifton, 1973, p.5). The relationship between creativity and symbolic immortality has been discussed by various prominent scholars. Rank (1968) and Becker (1973) considered the creative action to be a key route to individuation and unique self-expression and as an avenue for immortality, and Yalom (1980) referred to role of leaving behind an imperishable legacy in assuaging death concerns. Similarly, Lifton $(1973,1979)$ proposed the mode of creativity as a path for attaining symbolic immortality. On a similar vein, selfactualization and openness to experience, two constructs associated with creativity, have been proposed to reduce the terror of death (Maslow, 1970; Rogers, 1980). In this article, we will review the evidence on the relationship between creativity and symbolic immortality and present novel findings on the anxiety buffering functions of creative achievement.

The relationship between creativity and symbolic immortality is present in everyday life, as reflected in anecdotal evidence. British fashion designer Alexander McQueen described spreading his designs "so that when I'm dead and gone people will know that the $21^{\text {st }}$ century was started by Alexander McQueen” (Victoria and Albert Museum, 2015). Gyorgy Fauldy, the Hungarian poet and writer, when asked in his interview by Csikszentmihalyi (1996) why he decided to become a poet replied "Because I was afraid to die" (p.38). Other examples highlight 
the existential impact of the destruction or denunciation of creative achievements. In 2015, Islamic State militants destroyed multiple ancient monuments and artifacts in Iraqian sites such as Nimrod and Mosul (Shaheen, 2015), evoking calls of condemnation from officials worldwide. Finally, Yoshiki Sasai, a notable Japanese scientist in the field of stem-cell research who supervised and co-authored research papers that were published in Nature suffered their subsequent retraction due to falsified contents. Cutting short his long trajectory of creative achievement, Sasai was later found dead in an apparent suicide (Nature News, 2014). These examples support the notion that creativity is linked to death and its transcendence through the generation (or destruction) of enduring creative achievements.

The study of Big-C (eminent) creativity (Kaufman \& Beghetto, 2009) focuses on creative genius and creative greatness by analyzing the lives and works of well-known creators (e.g., Anais Nin (Kehagia, 2009) ; Frank Lloyd Wright (Weisberg, 2011)), interviewing renowned persons (Csikszentmihalyi, 1996), or studying people who score high on creativity measures (Kaufman \& Beghetto, 2009). These approaches have yielded limited evidence in support of the relationship between creativity and symbolic immortality. For example, in an observational study, the works of 172 classical composers were analyzed (Simonton, 1989). It was found that composers' last works were characterized by higher repertoire popularity and aesthetic significance and lower melodic originality and performance duration. This effect was found also after controlling for variables such as eminence, total composition output, and the composer's age when composing the final works. According to Simonton (1989), the melodic simplicity and conciseness of composers' final works suggest that as composers approached death, they became more invested in writing pieces that will secure their reputation over time. In line with this, significant inverse correlations were found between self-reports of a biological-creative mode of 
symbolic immortality (representing the enduring existential benefits of procreation and productivity) and fear of death (Florian \& Mikulincer, 1998).

\section{Terror management theory}

One theory for studying the relationship between creativity and symbolic immortality is Terror Management Theory (TMT; Greenberg, Pyszczynski, \& Solomon, 1986), an established theory in the field of social psychology. Largely derived from the works of cultural anthropologist Ernest Becker $(1971,1973)$ and psychoanalyst Otto Rank (1941), TMT proposes that the awareness of death serves as a critical motivator of human behavior. Human beings, like other organisms, are driven by a self-preservation instinct, yet they are unique in their cognitive capacity to understand their finitude. The conflict between one's mortality awareness and survival goals creates an existential paradox, which may lead to experiencing severe anxiety, or terror. The theory maintains that in order to defend oneself from this potential terror, people invest in two interrelated psychological structures. The first is a cultural worldviews: a set of socially constructed and validated beliefs that provide meaning, order, a set of principles to live by, and the promise of either literal (i.e., promise of an after-life) or symbolic immortality to socially valued individuals. The second death-anxiety buffering structure is self-esteem. By living up to the standards of value prescribed by cultural worldviews or behaving in culturally valued manner, one achieves a high level of self-esteem. Consequently, as a valuable contributor to something larger, more meaningful, and longer lasting than mere physical existence, one gains the protection from mortality concerns offered by the culture. According to TMT, symbolic immortality may be achieved via long-lasting creative achievements in art or science, perceiving oneself as belonging to a culture extending beyond one's lifetime, having children, and concrete testaments to one's existence such as impressive monuments or great wealth (Solomon, 
Greenberg, \& Pyszczynski, 2004). Since its inception, TMT has gained empirical support from hundreds of experiments worldwide (Landau, Sullivan, \& Solomon, 2010; Pyszczynski, Solomon, \& Greenberg, 2015).

TMT studies on creativity typically utilize the Mortality Salience (MS) hypothesis (Rosenblatt, Greenberg, Solomon, Pyszczynski, \& Lyon, 1989). The MS hypothesis states that if adhering to cultural worldviews and self-esteem buffers mortality concerns, then making mortality salient should increase individuals' need for this symbolic protection, consequently motivating them to uphold, defend, and maintain their worldviews, and strive for enhancing selfesteem. Indeed, mortality reminders have been found to produce various reactions directed toward securing self-esteem and faith in one's cultural worldview (e.g., increased upholding of social values, nationalistic biases; for reviews, see Burke, Martens, \& Faucher, 2010; Pyszczynski, Greenberg, Solomon, Arndt, \& Schimel, 2004) . In a standard experimental design of MS studies, participants in the MS condition complete a measure that prompts them to consider their own mortality while control participants complete a parallel measure on a neutral or aversive topic (e.g., extreme pain). Additional details on variations in mortality inductions and in control conditions are available elsewhere (e.g., Hayes et al., 2010; Landau et al., 2010).

It has been proposed that creativity relates to death in various ways including through its death-denying and life affirming properties (Abra, 1995). In providing an experimental paradigm for examining symbolic mortality strivings, TMT enables the incorporation of empirical evidence into the extant literature on the relationship between creativity and death. Nonetheless, TMT studies on creativity have not been previously described as a whole. In order to promote our understanding of the relationship between creativity and symbolic immortality, we will first 
examine empirical evidence on the relationship between creativity and symbolic immortality from a TMT perspective.

\section{Creativity and Terror Management Theory}

Overall, we have identified 12 papers that examined the relationship between creativity and mortality awareness using a TMT paradigm. Research thus far focused on four main lines of investigation, namely, socio-cultural effects of creative performance following MS, the effects of MS on creative performance, the effect of leaving a legacy on creative performance following MS, and the role of individual trait differences in moderating the effect of MS on creative performance or creative interest. These are presented in detail below. The characteristics of the 12 papers and their findings on the link between death awareness and creativity are presented in Table 1.

The socio-cultural effects of creative performance following MS. Four papers examined the effects of creative performance following MS on social and cultural constructs. Specifically, creative performance following MS has been found to increase assimilation needs (Arndt, Routledge, Greenberg, \& Sheldon, 2005), guilt and social projection (Arndt, Greenberg, Solomon, Pyszczynski, \& Schimel, 1999), and worldview exploration (Routledge \& Arndt, 2009), and to decrease nationalistic worldview defense (Routledge, Arndt, \& Sheldon, 2004). Findings from the former two papers suggest that to the extent that creativity is an avenue for individuation, it implies a threat to prevailing cultural worldviews. Consequently, when death is salient and needs for cultural worldview validation are high, creativity may lead to adverse psychological outcomes such as guilt unless social ties are in place (Arndt et al., 1999; Arndt et al., 2005). Findings from the latter two papers suggest that creativity, through its association with divergent thinking and open-mindedness, may promote openness towards divergent worldviews 
in order to maintain psychological security in the face of death (Routledge et al., 2004;

Routledge \& Arndt, 2009). Taken together, the above findings highlight the interplay between creativity, cultural worldviews, and symbolic immortality strivings. Specifically, when death is salient, creativity may promote a more flexible management of symbolic immortality needs (e.g., Routledge \& Arndt, 2009), and may confer existential benefits if it is compatible with one's cultural worldviews.

The effects of MS on creative performance. Three papers examined the effects of MS on creative performance (Greenberg, Porteus, Simon, Pyszczynski, \& Solomon, 1995; Long \& Greenwood, 2013; Routledge, Arndt, Vess, \& Sheldon, 2008). Of these three papers, one paper examined creative performance that either threatened social connections (self-oriented creative performance condition) or enhanced social connections (community-oriented creative performance condition). It was found that MS significantly decreased creativity for participants in the self-oriented condition, but not for participants in the community-directed condition, when compared to control participants (Routledge et al., 2008). These findings suggest that when death is salient, creativity may be enhanced when it is compatible with pro-social cultural worldviews (Routledge et al., 2008). Another paper examined the effects of explicit and implicit MS on humorous captions' generation, as rated by raters or self-rated (Long \& Greenwood, 2013). It was found following MS, creativity tapped as humor production was facilitated when selfassessed under explicit MS. When other-assessed, creativity was enhanced when using subliminal death primes, but hindered when MS was explicit (Long \& Greenwood). These findings highlight the need to be mindful of priming modality and creativity assessment methods in order to promote our understanding of MS on humor production (Long \& Greenwood). Finally, one paper examined the use of cultural objects in two practical tasks (Greenberg et al., 
1995). Participants were requested to separate sand from a black dye (task 1) and to hang a crucifix on the wall (task 2) using an object of their choice. Available objects included either cultural (i.e., flag, crucifix, respectively; cultural-objects condition) or neutral (i.e., white cloth, block of wood, respectively; neutral-objects condition) objects. It was found that MS participants in the cultural-objects condition took significantly longer to complete the tasks and considered significantly more alternative solutions in comparison to MS participants in the neutral-objects condition and controls (Greenberg et al., 1995). These findings suggest that when death and cultural icons are salient, problem-solving creativity may decrease while creative fluency may increase. It may be that while MS increased creativity, this was countered by increased avoidance of cultural worldviews violation by the manipulation of cultural objects (Greenberg et al., 1995). Taken together, the above evidence highlight the link between existential motives, death awareness, and creativity, and suggest that when death is salient, the creative act may be shaped by its existential meanings.

In order to enhance the state of knowledge on the relationship between MS and creativity, and considering the comparability of the studies in the above three papers, we conducted a mini meta-analysis on the impact of MS on creativity (Table 2). The inclusion criteria were: 1. papers categorized as examining the effects of MS on creative performance; and 2. having an otherassessed creativity-related DV. A positive effect size (Cohen's $d$ ) indicates greater creativity under MS in comparison to the control condition. When the MS condition had more than one cell, we selected the condition that theory predicted would result in increased creativity. To enable inferences beyond these studies, we used random-effects models, which assume different effect sizes may be underlying each study and enable inferences beyond these studies (Borenstein, Hedges, Higgins, \& Rothstein, 2010). We contacted the first authors of all three 
papers with requests for additional data. Effect sizes were calculated using an online calculator (Lipsey \& Wilson, 2001), based on $M, S D$ s, and $n$ per cell, where data was made accessible. When that was not the case, effect sizes were calculated based on the data presented in the paper. To correct for the upward bias of effect sizes in small samples, we applied the formula provided by Hedges (1981). The meta-analysis was conducted on SPSS 19.0 using syntax provided by Field \& Gillett (2010). Heterogeneity was not significant, $p>.47$, indicating no systematic relationship between study attributes and effect sizes. The weighted mean effect size for the relationship between MS and creativity was 0.30, representing a small to medium effect by Cohen's (1988) criteria. In the field of psychology, this effect size is comparable to the mean effect size in motivation studies (Richard, Bond Jr, \& Stokes-Zoota, 2003).

Legacy effects on creative performance following MS. The effect of leaving a legacy on creative performance following MS was examined in a single paper presenting a series of studies (Sligte, Nijstad, \& De Dreu, 2013). In two studies, the creative task was naming an animal in a zoo, and legacy was manipulated by the animal's life expectancy, that is, short (no legacy) vs. long (legacy). It was found that MS participants in the legacy condition had significantly higher levels of originality in comparison to those in the no-legacy condition (study 1). When manipulating the social value of naming an animal, it was found that the same pattern persisted when the task was socially valuable, but not when it was not socially valuable (study 2). Taken together, these findings suggest that the promise of legacy increases creativity when death is salient, particularly when creativity is aligned with cultural worldviews (Sligte et al., 2013). In study 3 , the creative task involved brainstorming on ways to improve the environment, and legacy was manipulated by whether one's ideas will bear one's name and will be transferred for others to use. It was found that after performing a creative task, MS participants had higher 
Death-Thought Accessibility (DTA) under legacy when compared to no legacy (study 3) (Sligte et al., 2013). The authors suggested this finding may be due to the experience of guilt following the creative task, which consequently led to higher DTA (Sligte et al., 2013). Indeed, considering the fact that participants completed an individualism-collectivism questionnaire prior to the creative task, it may be that individualism concerns were primed when mortality was salient, resulting in guilt (Arndt et al., 1999). Nonetheless, the finding demonstrates the relationship between enduring creative products, MS, and DTA.

Individual differences in MS effects on creativity. The role of individual trait differences in moderating the effect of MS on creative performance or creative interest has been examined in five papers. Personal Need for Structure (PNS) reflects the extent of one's wish to perceive the world in clear, unambiguous terms (Thompson, Naccarato, Parker, \& Moskowitz, 2001). In response to mortality reminders, persons with low PNS demonstrated increased creativity as measured by a T-shirt design task while the creativity of persons with high PNS was unaffected (Routledge \& Juhl, 2012). In another study, a creativity task was used as an indicator for participants' decision-making patterns. Following MS, participants were asked to select one of six design patterns that offered differing degrees of creative expression. It was found that persons with high, but not low, self-esteem opted for a high-risk creativity task which allowed greater creative expression (Landau \& Greenberg, 2006; study 3) . Others have found that participants with lower, but not higher, levels of neuroticism had significantly increased creative interest following MS (Xu \& Brucks, 2011). Another paper examined the relationships between creative interest, creative tendency, and DTA, yielding mixed results (Xu, Brucks, \& Guo, 2013). Finally, in the aforementioned study by Sligte et al. (2013; study 3), it was found that MS participants with high, but not low, levels of individualism in the legacy condition had 
significantly higher levels of originality and creative fluency in comparison to those in the nonlegacy condition. Overall, the above studies show that personal traits' differences may moderate the effect of MS on creativity. In particular, findings suggest that persons who are more existentially secure (e.g., higher self-esteem; Abeyta, Juhl, \& Routledge, 2014) or have less to benefit from rigid worldview defense (e.g., low PNS; Juhl \& Routledge, 2010) may manage symbolic immortality needs in the face of death more flexibly. Consequently, creativity may be enhanced, particularly when it involves legacy.

\section{The Current Study}

The above review of TMT literature on creativity highlights various elements in the relationship between creativity and death. In terms of creativity facilitation, these include the potential preconditions for creativity to be existentially beneficial (i.e., compatibility with cultural worldviews) and the role of leaving a legacy in enhancing creativity when death is salient. In terms of existential value, the evidence demonstrate the loosing effect of creativity on the management of symbolic immortality needs when death is salient, and the link between legacy, death awareness, and DTA. Overall, the bulk of the evidence reviewed support the notion that creativity plays an important role in the management of existential concerns. It follows that creativity may serve as an existential anxiety buffer in the face of death. Indeed, the association between creative achievement and symbolic immortality has been supported both theoretically (Lifton, 1973; Solomon et al., 2004) and by observational research (Simonton, 1989). Nonetheless, while one paper included a manipulation of legacy (Sligte et al., 2013), the relationship between creative achievement and symbolic immortality has not yet been directly examined. 
If creativity is an avenue to symbolic immortality, then the promise of impactful, longlasting cultural contributions inherent in creative achievement should be associated with lesser DTA when death is salient. However, it is noteworthy that high levels of creative achievement are generally exhibited by a minority of persons within a given population (Eysenck, 1995). Accordingly, creative achievement may not comprise a universal existential anxiety buffer but rather one that is valuable for persons who value and pursue creativity as a central part of their worldview. From a TMT perspective, this means that creative achievement may work in tandem with creativity-related cultural worldviews in order to buffer against the awareness of death. In addition, it has been found that conscious thoughts of death lead to higher DTA after a delay, once active suppression relaxes (e.g., Greenberg, Pyszczynski, Solomon, Simon, \& Breus, 1994). Accordingly, if creative achievement is an existential anxiety buffer, then it should defend against elevated DTA following MS, particularly among those who value and pursue creativity. We hypothesize that creative achievement would be associated with lesser DTA among persons who value, but not among persons who do not value, creativity, after MS in comparison to controls.

\section{Methods}

\section{Participants and Recruitment}

Participants were 108 undergraduate psychology students, ${ }^{1}$ aged $18-33\left(\mathrm{M}_{\text {age }}=19.74, \mathrm{SD}_{\text {age }}=\right.$ 2.57), of whom $79 \%$ were female. Students received partial course credit for their participation.

\section{Procedure}

\footnotetext{
${ }^{1}$ Five participants identified the manipulation, and 3 participants showed response bias. Accordingly, these 8 participants were excluded from analysis. All data exclusions are reported in accordance with APA standards.
} 
This online study had a 2 (creative achievement: high, low) X 2 (creative goals: high, low) X 2 (mortality salience: high, low) between-subjects design and was presented as a study on personality. Participants completed measures of creative achievement and creative goals that were embedded within filler questionnaires. Next, participants were randomly allocated to the MS condition or the control condition, and completed either the MS or control measurement, respectively. This was followed by the PANAS, which served as a delay and distraction task because previous research has shown that MS effects are manifested when persons no longer attend consciously to thoughts elicited by the manipulation (Greenberg et al., 1994). Participants proceeded to complete the dependent variable, the DTA measure (Greenberg et al., 1994). Finally, participants were asked what in their opinion was the purpose of the study, provided demographic details, and were thanked and debriefed.

\section{Materials}

Creative achievement. Creative achievement was assessed by the Creative Achievement Questionnaire (CAQ; Carson, Peterson, \& Higgins, 2005). The CAQ measures creative accomplishments in 10 domains (e.g., visual arts, music, inventions) via self-report while focusing on concrete public accomplishments (e.g., reviews in national publications). The scoring of the CAQ assigns higher weights to higher levels of creative achievements, which typically leads to a positively skewed distribution of the data (Carson et al., 2005). The index score was computed as the mean of ratings across domains. Because the 10 domains do not seem to have one underlying factor (Carson et al., 2005; Silvia, Kaufman, \& Pretz, 2009), the calculation of a meaningful internal consistency measure is hindered. The CAQ demonstrated good test-retest reliability $(r=.81)$ and good discriminant validity in a sample of students 
(Carson et al., 2005), and can be used to detect both individual and group differences in creative achievement (Carson, Peterson, \& Higgins, 2003).

Creative goals. A measure of creative goals was custom designed for this study based on the WASSUP (Willingly Approached Set of Statistically Unlikely Pursuits; Johnson \& Carver, 2006) in order to operationalize the pursuit of creative goals, i.e., having creativity as a central part of one's cultural worldview. The measure included four items $(\mathrm{a}=.79)$ : 1 . You will produce a great creative work; 2. You will make an important contribution in the field of art or science; 3. Your creative work will be acknowledged by experts in your field; 4 . You will create work with enduring value that is original and useful. In order to obscure the purpose of this measure, the above items were embedded within the 5-item WASSUP friends subscale (e.g., "You will have 10 close friends"). Items were rated on the WASSUP scale, ranging from 1 (NO CHANCE I will set this goal for myself) to 5 (Definitely WILL set this goal for myself). To examine the factorial structure of the creative goals measure, we conducted an exploratory factor analysis using the Maximum Likelihood method. The analysis and scree plot confirmed the one-dimensionality of the measure, accounting for $62 \%$ of the variance, $\mathrm{KMO}=.75, \chi^{2}(2)=5.65, p=.06$.

Mortality Salience. In the MS condition, participants completed the Fear of Death scale (Templer, 1970), which is comprised of 15 true/false statements (e.g., "I am very much afraid to die"). Control participants completed 15 parallel statements on fear of public speaking (e.g., "I am very much afraid to speak in public") (Cox et al., 2009).

Affect. Affect was assessed by the 20-item Positive and Negative Affect Scales (PANAS; Watson, Clark, \& Tellegen, 1988). Items were rated on a scale ranging from 1 (very slightly or not at all) to 5 (extremely). A total score was computed for positive affect (10 items; $\mathrm{a}=.88$ ) and negative affect ( 10 items; $\mathrm{a}=.91)$ as the mean of items' ratings. 
Death-thought accessibility. The accessibility of death thoughts was assessed using a 25-item word fragment completion task, in which six words could be completed as either deathrelated words or death-unrelated words (Arndt, Greenberg, Solomon, Pyszczynski, \& Simon, 1997). For example, the word fragment "SK__ L" could be completed as either SKULL (deathrelated) or SKILL (death-unrelated). The possible death-related words were buried, dead, decay, skull, grave, and old. The number of death-related words served as the DTA measure. To ascertain that DTA is independent of negative-thought accessibility, six of the 25 word stems could be completed as either negative (death-unrelated) words or neutral words (Hart, 2014; Yaakobi, 2015). The possible negative words were stress, sad, pain, guilt, sorrow, and shame. For example, the word fragment "STRE__" could be completed as either STRESS (negative) or STREET (neutral). The number of negative words served as the negative-thought accessibility measure.

\section{Results}

Descriptive statistics for the study independent variables are shown in Table 3. There were no significant correlations between the study independent variables, $p$ s $>.77$.

To examine the effect of creative achievement, creative goals, and condition on DTA, we conducted a linear regression. The independent variables creative achievement (centered), creative goals (centered), and condition (dummy coded) were entered in the first step, interaction terms for each two combinations were entered in the second step, and the interaction term for the three predictors was entered in the third and final step. The dependent variable was DTA. The results of the regression are presented in Table 4. In the first and second steps of the regression, no effects were significant. In the final model, there were no significant main effects or 2-way interaction effects. As predicted, there was a significant 3-way interaction between creative 
achievement, creative goals, and condition, $\beta=-.35, \mathrm{~B}=-.45$, Standard Error $(\mathrm{SE})=.22, \mathrm{t}=-$ 2.02, $p=.046,95 \%$ Confidence interval $(\mathrm{CI})=-0.88--0.01, \mathrm{R}^{2}=.10$.

To follow-up on the 3-way interaction, we used the SPSS PROCESS macro, Model 3 (moderated moderation) (Hayes, 2013). The independent variable (X) was condition (dummy coded). The moderator (M) was creative achievement (centered). The proposed moderator (W) was creative goals (centered). The dependent variable (Y) was DTA. The breakdown of the 3way interaction is shown in Figure 1a for high levels of creative goals and in Figure 1b for low levels of creative goals. It was found that the relationship between creative achievement and condition was significant at high levels $(+1 \mathrm{SD})$ of creative goals, $\mathrm{B}=-.96, \mathrm{SE}=.42, \mathrm{t}=-2.29, p$ $=.02,95 \% \mathrm{CI}=-1.79--0.13$, and nonsignificant at low levels $(-1 \mathrm{SD})$ of creative goals, $p>.85$. Thus, as predicted, only among people with high creative goals, creative achievements were associated with reduced DTA under MS. Next, we examined the effect of condition on DTA at high levels of creative goals. Among participants with low levels of creative achievement, the observed patterns suggest that MS was associated with increased DTA, B $=.90, \mathrm{SE}=.52, \mathrm{t}=$ $1.75, p=.08,95 \% \mathrm{CI}=-0.12-1.93$. Among those with high levels of creative achievement, MS was associated with decreased DTA, $\mathrm{B}=-.83, \mathrm{SE}=.47, \mathrm{t}=-1.75, p=.08,95 \% \mathrm{CI}=-1.76-$ 0.11. Although the latter patterns are marginally significant, taken together the results show that only participants with high levels of creative goals and high creative achievements showed reduced DTA after reminders of mortality as compared to the control condition. In order to examine the regression analysis for multivariate outliers and their levels of influence, we followed the guidelines provided by Stevens (1984). First, we computed Mahalanobis Distances (MD), $\mathrm{M}=6.93, \mathrm{SD}=10.12$. Considering our analysis had three predictors and a sample size of approximately $\mathrm{n}=100, \mathrm{MD}>16.45$ was selected as the cut-off point for multivariate outliers. 
Seven cases exceeded this cut-off point. Second, to determine if any of these seven cases were influential points, we calculated Cook distances, $\mathrm{M}=0.01, \mathrm{SD}=0.05$. Cook distances for all of the seven cases were <.46, i.e., below the cut-off point for influential outliers of > 1 . Thus, no influential multivariate outliers were found.

In order to exclude the possibility that the interaction effect was due to affect, we re-ran the analysis with negative-thought accessibility as a covariate, and with positive and negative affect as covariates. In these two separate analyses, the 3-way interaction remained significant, $p s<.05$. To examine if the effect of the interaction is specific to DTA, we ran the original analysis with negative-thought accessibility, negative affect, and positive affect as the dependent variable. In each of these three separate analyses, the interaction was not significant, $p s>.47$. These findings support the notion that the decrease in DTA among persons with high levels of creative goals and high creative achievements after MS in comparison to controls is not due to changes in affect.

\section{Discussion}

The relationship between creativity and symbolic immortality has been long acknowledged by a wide range of scholars. In a narrative review of the literature, we found 12 papers that examined creativity utilizing a TMT paradigm. Overall, these TMT studies revealed that reminders of mortality can facilitate creativity within the context of people's cultural and personal values. Furthermore, it was found that death awareness affects the pursuit of social and psychological needs after creative engagement. A mini meta-analysis of the impact of death awareness on creativity resulted in a small-medium weighted mean effect. Thus, the presented findings suggest that creativity (for those who value creativity) may function as an existential anxiety buffer that helps to manage existential concerns. In view of this, we examined the anxiety buffering 
functions of creative achievement in an experimental study that manipulated death awareness. It was found that among participants with high, but not low, levels of creative goals, creative achievement was associated with reduced DTA under MS as compared to the control condition. These findings show that creative achievement serves as an existential anxiety buffer, particularly among people for whom creativity constitutes a central part of their cultural worldview.

\section{Creative achievement and Terror Management Theory}

From a TMT perspective, current findings are in line with a host of evidence on increased strivings for various forms of symbolic immortality in response to death reminders. In line with Lifton's (1973) notion of one's enduring contributions as way to attain symbolic immortality research revealed that MS can increase; the willingness to self-sacrifice for an ideological cause (Routledge \& Arndt, 2007), legacy-building needs (Wade-Benzoni, Tost, Hernandez, \& Larrick, 2012), the appeal of fame (Greenberg, Kosloff, Solomon, Cohen, \& Landau, 2010), the desire to work (Yaakobi, 2015), and the desire for offspring (Fritsche et al., 2007; Wisman \& Goldenberg, 2005). The current findings support the notion that creative achievement may be yet another avenue for symbolic immortality, particularly among individuals who value creativity. Importantly, the current study represents an important first step towards establishing creative achievement as an anxiety-buffering mechanism (see Harmon-Jones et al., 1997). According to TMT, one way to cope with death awareness is to re-affirm one's cultural worldviews and beliefs (Greenberg et al., 1990), for example by endorsing moral values (Bassett, Van Tongeren, Green, Sonntag, \& Kilpatrick, 2015). To further examine the anxiety buffering properties of creative achievement, it may be useful to focus on creativity-related worldview defense measures. Specifically, because values such as self-direction and universalism are valued by creative 
persons and are associated with creative accomplishment (Dollinger, Burke, \& Gump, 2007), threatening these values, for example by presenting an essay that derogates them, may lead to their defense in creative individuals when death is salient. However, high levels of creative achievement may buffer this effect, so that highly accomplished creative persons would not show an increase in worldview defense under MS. Because lesser endorsement of values such as universalism is associated with less concern for others and society as a whole (Schwartz, 2007), this line of future research may have implications for understanding the existential underpinnings of immoral behaviors in creative pursuits (Vincent \& Polman, 2016).

\section{Creative Achievement and Symbolic Immortality: A Mixed Blessing?}

The integration of creative achievement and TMT research has important implications for the field of creativity research. If creative achievement can function as an existential anxiety buffer, than creativity may inspire creative motives that function to defeat, deny, and cope with the everpresent awareness of death (Abra, 1995). Although creativity is in general associated with positive contributions to humanity, the need to understand the dark side of creativity (Cropley, Kaufman, \& Cropley, 2008) is highlighted by events such as the 2015 Paris attacks. In terrorist organizations, achievement motivations may contribute to destructive innovations (Gill, Horgan, Hunter, \& Cushenbery, 2013). Thus, understanding which death-related motivations underlie malevolent creative acts could enhance counter-terrorism practices. The existential functions of creative achievement may operate by conferring collective symbolic immortality ("My cultural contribution will outlive me") (Lifton, 1973) or personal symbolic immortality ("I will be remembered after I die") (Shneidman, 1973; Wojtkowiak \& Rutjens, 2011). Accordingly, deathrelated motivations of malevolent creativity, that is, creativity driven by consciously negative intentions that yields personal benefits for the creator but has negative consequences for others 
(Cropley et al., 2008) may be driven by the desire to leave an enduring, albeit destructive cultural impact (e.g., the 9/11 attacks) or by the promise of a personal legacy after death (e.g., remembrance as martyr). It would therefore be opportune to examine the role of personal or collective immortality motivations in different malevolent creative acts (e.g., ideological vs. selfpromoting malevolent self-sacrifice). In addition, creative acts of different valence may have a different impact on collective existential security levels. Future studies could examine if conscientious creativity, that is, ethical, constructive creativity that is driven by positive intentions and has positive consequences for society (Kampylis \& Valtanen, 2010) confers collective existential protection through increasing personal hope or a belief in human socialmoral progress (Rutjens, van Harreveld, van der Pligt, van Elk, \& Pyszczynski, 2016; Wisman \& Heflick, 2016). Conversely, studies could determine if there is an adverse collective existential impact to malevolent creative acts. For example, failure to prevent terrorist attacks is likely to arouse outrage at the state's inability to provide protection (Fischbacher-Smith, 2016), thus undermining the symbolic existential protection conferred by national identity and symbols (e.g., Greenberg et al., 1990). Overall, creative achievements may be driven by different existential motivations and have valence-specific collective outcomes. Thus, the current findings may contribute to the construction of a new framework to understand the underpinnings and impact of death-motivated creative pursuits.

\section{Practical implications}

In terms of practical implications, understanding the impact of creativity on existential concerns and consequently on everyday attitudes and behaviors may serve to promote creative achievement, thus benefiting individuals (Plucker, Beghetto, \& Dow, 2004) and advancing human achievement (Forster, 2012). Creativity is facilitated by person variables (Rhodes, 1961) 
such as risk-taking (Davis, Rimm, \& Siegle, 2011; Sternberg, 2006), intrinsic motivation (Amabile, 1983; Kieran, 2014), and perseverance in face of initial difficulties (Sternberg, 2006). Accordingly, associating creativity with existential security may promote creative achievement in individuals by increasing perceived (symbolic and everyday) benefits and decreasing perceived costs of creative pursuits (e.g., risky investment). Understanding the existential meanings of an enduring creative achievement may be particularly valuable for expert (Pro-c) creative persons as they navigate motivational and creative challenges en route to eminence (Big-C) (Kaufman \& Beghetto, 2009; Olszewski-Kubilius, Subotnik, \& Worrell, 2016), for example, by identifying clear goals in terms of impact on the field (Amabile \& Kramer, 2011). In educational settings, communicating the link between creativity and existential security may be valuable in enhancing students' positive beliefs regarding their creative pursuits (Wadaani, 2015) as a part of a wider strategy of supporting students' intrinsic creativity motivations in their learning environment (Beghetto \& Kaufman, 2014). Overall, the findings of the current study may be useful in promoting creative achievement and creative motivation in people with varying levels of creative expression.

\section{Limitations}

The current study is not without limitations. The sample in this study consisted of psychology students. It has been shown that students or graduates of non-creative professions have significantly lower levels of creative achievement in comparison to those of creative professions (Silvia \& Nusbaum, 2012; Vellante et al., 2011). This suggests that the anxiety buffering functions of creative achievement may be more robust among students of creative professions, who by definition consider creativity as central to their cultural worldview (Dollinger et al., 2007). By the same token, future studies may examine the anxiety buffering functions of creative 
achievement in individuals with established high levels of creative achievement (e.g., ChavesEakle, del Carmen Lara, \& Cruz-Fuentes, 2006), who may be particularly resilient to the awareness of death. Finally, our mini meta-analysis represents the current state of knowledge on the relationship between death awareness and creativity. While the small number of studies included may limit its precision (Borenstein et al., 2010), the interpretation of this analysis is enhanced by the narrative review.

\section{Conclusion}

The current study is the first to show the existential anxiety-buffering functions of creative achievement among persons with high creative goals. Specifically, we found that creative achievement was linked to lower DTA under MS in comparison to controls among persons with high creative goals. In line with Rank's (1968) notion of the artist's desire self-immortalize in one's work, our findings suggest that those who pursue creativity and produce significant creative contributions may benefit from existential security in the face of death. The current findings, narrative review, and mini meta-analysis advance existing research on the link between creativity and death, and have implications for the promotion of creative achievement and intrinsic motivation in creative individuals and in educational settings. The integration of creativity and TMT provides a promising (and creative) avenue for understanding death-related creativity motivations and their impact on individuals and society for scholars, educational policy makers, and creative persons. 


\section{References}

Abeyta, A. A., Juhl, J., \& Routledge, C. (2014). Exploring the effects of self-esteem and mortality salience on proximal and distally measured death anxiety: A further test of the dual process model of terror management. Motivation and Emotion, 38(4), 523-528.

Abra, J. (1995). Do the muses dwell in elysium? Death as a motive for creativity. Creativity Research Journal, 8(3), 205-217.

Amabile, T., \& Kramer, S. (2011). The progress principle: Using small wins to ignite joy, engagement, and creativity at work. Boston, MA: Harvard Business Press.

Amabile, T. M. (1983). The social psychology of creativity: A componential conceptualization. Journal of Personality and Social Psychology, 45(2), 357-376.

Arndt, J., Greenberg, J., Solomon, S., Pyszczynski, T., \& Schimel, J. (1999). Creativity and terror management: Evidence that creative activity increases guilt and social projection following mortality salience. Journal of Personality and Social Psychology, 77(1), 19-32.

Arndt, J., Greenberg, J., Solomon, S., Pyszczynski, T., \& Simon, L. (1997). Suppression, accessibility of death-related thoughts, and cultural worldview defense: Exploring the psychodynamics of terror management. Journal of Personality and Social Psychology, $73(1), 5-18$.

Arndt, J., Routledge, C., Greenberg, J., \& Sheldon, K. M. (2005). Illuminating the dark side of creative expression: Assimilation needs and the consequences of creative action following mortality salience. Personality and Social Psychology Bulletin, 31(10), 13271339.

Bassett, J. F., Van Tongeren, D. R., Green, J. D., Sonntag, M. E., \& Kilpatrick, H. (2015). The interactive effects of mortality salience and political orientation on moral judgments. British Journal of Social Psychology, 54(2), 306-323. 
Becker, E. (1971). The birth and death of meaning. New York: Free Press.

Becker, E. (1973). The denial of death. New York: Free Press.

Beghetto, R. A., \& Kaufman, J. C. (2014). Classroom contexts for creativity. High Ability Studies, 25(1), 53-69.

Borenstein, M., Hedges, L. V., Higgins, J., \& Rothstein, H. R. (2010). A basic introduction to fixed-effect and random-effects models for meta-analysis. Research Synthesis Methods, l(2), 97-111.

Burke, B. L., Martens, A., \& Faucher, E. H. (2010). Two decades of terror management theory: A meta-analysis of mortality salience research. Personality and Social Psychology Review, 14(2), 155-195.

Butcher, J. N., Dahlstrom, W. G., Graham, J. R., Tellegen, A., \& Kaemmer, B. (1989). MMP1-2 manual for administration and scoring. Minneapolis: University of Minnesota Press.

Carson, S. H., Peterson, J. B., \& Higgins, D. M. (2003). Decreased latent inhibition is associated with increased creative achievement in high-functioning individuals. Journal of Personality and Social Psychology, 85(3), 499-506.

Carson, S. H., Peterson, J. B., \& Higgins, D. M. (2005). Reliability, validity, and factor structure of the creative achievement questionnaire. Creativity Research Journal, 17(1), 37-50.

Chavez-Eakle, R. A., del Carmen Lara, M., \& Cruz-Fuentes, C. (2006). Personality: A possible bridge between creativity and psychopathology? Creativity Research Journal, 18(1), 2738.

Cohen, J. (1988). Statistical power analysis for the behavioural sciences (2 ed.). New York: Academic Press. 
Cox, C. R., Cooper, D. P., Vess, M., Arndt, J., Goldenberg, J. L., \& Routledge, C. (2009). Bronze is beautiful but pale can be pretty: The effects of appearance standards and mortality salience on sun-tanning outcomes. Health Psychology, 28(6), 746-752.

Cropley, D. H., Kaufman, J. C., \& Cropley, A. J. (2008). Malevolent creativity: A functional model of creativity in terrorism and crime. Creativity Research Journal, 20(2), 105-115.

Csikszentmihalyi, M. (1996). Creativity: Flow and the discovery of invention. New York, US: HarperCollins Publishers.

Davis, G., Rimm, S., \& Siegle, D. (2011). Education of the Gifted and Talented. Boston, MA: Pearson Education.

Dollinger, S. J., Burke, P. A., \& Gump, N. W. (2007). Creativity and values. Creativity Research Journal, 19(2-3), 91-103.

Eysenck, H. J. (1995). Genius: The nautral history of creativity. Cambridge, UK: Cambridge University Press.

Feldman, D. H., Csikszentmihalyi, M., \& Gardner, H. (1994). Changing the world: A framework for the study of creativity. Westport, CT: Praeger Publishers.

Field, A. P., \& Gillett, R. (2010). How to do a meta-analysis. British Journal of Mathematical and Statistical Psychology, 63(3), 665-694.

Fischbacher-Smith, D. (2016). Framing the UK's counter-terrorism policy within the context of a wicked problem. Public Money \& Management, 36(6), 399-408.

Florian, V., \& Mikulincer, M. (1998). Symbolic immortality and the management of the terror of death: The moderating role of attachment style. Journal of Personality and Social Psychology, 74(3), 725-734. 
Forster, J. (2012). Creativity: The hub of real achievement. Gifted Education International, 28(3), 281-299.

Fritsche, I., Jonas, E., Fischer, P., Koranyi, N., Berger, N., \& Fleischmann, B. (2007). Mortality salience and the desire for offspring. Journal of Experimental Social Psychology, 43(5), 753-762.

Gill, P., Horgan, J., Hunter, S. T., \& Cushenbery, L. D. (2013). Malevolent creativity in terrorist organizations. The Journal of Creative Behavior, 47(2), 125-151.

Green, J. D., \& Campbell, W. K. (2000). Attachment and exploration in adults: Chronic and contextual accessibility. Personality and Social Psychology Bulletin, 26(4), 452-461.

Greenberg, J., Kosloff, S., Solomon, S., Cohen, F., \& Landau, M. (2010). Toward understanding the fame game: The effect of mortality salience on the appeal of fame. Self and Identity, 9(1), 1-18.

Greenberg, J., Porteus, J., Simon, L., Pyszczynski, T., \& Solomon, S. (1995). Evidence of a terror management function of cultural icons: The effects of mortality salience on the inappropriate use of cherished cultural symbols. Personality and Social Psychology Bulletin, 21(11), 1221-1228.

Greenberg, J., Pyszczynski, T., \& Solomon, S. (1986). The causes and consequences of a need for self-esteem: A terror management theory. In R. F. Baumeister (Ed.), Public self and private self (pp. 189-212). New York, NY: Springer-Verlag.

Greenberg, J., Pyszczynski, T., Solomon, S., Rosenblatt, A., Veeder, M., Kirkland, S., \& Lyon, D. (1990). Evidence for terror management theory II: The effects of mortality salience on reactions to those who threaten or bolster the cultural worldview. Journal of Personality and Social Psychology, 58(2), 308-318. 
Greenberg, J., Pyszczynski, T., Solomon, S., Simon, L., \& Breus, M. (1994). Role of consciousness and accessibility of death-related thoughts in mortality salience effects. Journal of Personality and Social Psychology, 67(4), 627-637.

Harmon-Jones, E., Simon, L., Greenberg, J., Pyszczynski, T., Solomon, S., \& McGregor, H. (1997). Terror management theory and self-esteem: Evidence that increased self-esteem reduced mortality salience effects. Journal of Personality and Social Psychology, 72(1), 24-36.

Hart, J. (2014). Toward an integrative theory of psychological defense. Perspectives on Psychological Science, 9(1), 19-39.

Hayes, A. F. (2013). Introduction to mediation, moderation, and conditional process analysis: A regression-based approach. New York: Guilford Press.

Hayes, J., Schimel, J., Arndt, J., \& Faucher, E. H. (2010). A theoretical and empirical review of the death-thought accessibility concept in terror management research. Psychological Bulletin, 136(5), 699-739.

Hedges, L. V. (1981). Distribution theory for Glass's estimator of effect size and related estimators. Journal of Educational and Behavioral Statistics, 6(2), 107-128.

Juhl, J., \& Routledge, C. (2010). Structured terror: Further exploring the effects of mortality salience and personal need for structure on worldview defense. Journal of Personality, 78(3), 969-990.

Kampylis, P. G., \& Valtanen, J. (2010). Redefining creativity: Analyzing definitions, collocations, and consequences. Journal of Creative Behavior, 44(3), 191-214.

Kaufman, J. C., \& Beghetto, R. A. (2009). Beyond big and little: The four C model of creativity. Review of General Psychology, 13(1), 1-12. 
Kieran, M. (2014). Creativity as a virtue of character. In E. S. Paul \& S. B. Kaufman (Eds.), The philosophy of creativity: New essays (pp. 125-146). New York: Oxford University Press.

Kugler, K., \& Jones, W. H. (1992). On conceptualizing and assessing guilt. Journal of Personality and Social Psychology, 62(2), 318-327.

Landau, M. J., \& Greenberg, J. (2006). Play it safe or go for the gold? A terror management perspective on self-enhancement and self-protective motives in risky decision making. Personality and Social Psychology Bulletin, 32(12), 1633-1645.

Landau, M. J., Sullivan, D., \& Solomon, S. (2010). On graves and graven images: A terror management analysis of the psychological functions of art. European Review of Social Psychology, 21(1), 114-154.

Lifton, R. J. (1973). The sense of immortality: On death and the continuity of life. American Journal of Psychoanalysis, 33, 3-15.

Lifton, R. J. (1979). The broken connection. New York: Simon \& Schuster.

Lipsey, M. W., \& Wilson, D. B. (2001). Practical meta-analysis. Thousand Oaks, CA: Sage.

Long, C. R., \& Greenwood, D. N. (2013). Joking in the face of death: A terror management approach to humor production. Humor, 1-17.

Marsh, H. W., \& O'Neill, R. (1984). Self description questionnaire III: The construct validity of multidimensional self-concept ratings by late adolescents. Journal of Educational Measurement, 21(2), 153-174.

Maslow, A. H. (1970). Motivation and personality. New York: Harper \& Row.

Nature News. (2014). Stem-cell scientists mourn loss of brain engineer. Retrieved May 29, 2015, from http://www.nature.com/news/stem-cell-scientists-mourn-loss-of-brainengineer-1.15679 
Olszewski-Kubilius, P., Subotnik, R. F., \& Worrell, F. C. (2016). Aiming talent development toward creative eminence in the 21st century. Roeper Review, 38(3), 140-152.

Plucker, J., Beghetto, R. A., \& Dow, G. (2004). Why isn't creativity more important to educational psychologists? Potential, pitfalls, and future directions in creativity research. Educational Psychologist, 39, 83-86.

Pyszczynski, T., Greenberg, J., Solomon, S., Arndt, J., \& Schimel, J. (2004). Why do people need self-esteem? A theoretical and empirical review. Psychological Bulletin, 130(3), $435-468$.

Pyszczynski, T., Solomon, S., \& Greenberg, J. (2015). Thirty years of terror management theory: From genesis to revelation. Advances in Experimental Social Psychology, 52, 1-70.

Rank, O. (1941). Beyond psychology. New York: Dover.

Rank, O. (1968). Art and artist: Creative urge and personality development. New York: W. W. Norton.

Rhodes, M. (1961). An analysis of creativity. The Phi Delta Kappan, 42(7), 305-310.

Richard, F. D., Bond Jr, C. F., \& Stokes-Zoota, J. J. (2003). One hundred years of social psychology quantitatively described. Review of General Psychology, 7(4), 331-363.

Rogers, C. R. (1980). A way of being. New York: Houghton-Mifflin.

Rosenblatt, A., Greenberg, J., Solomon, S., Pyszczynski, T., \& Lyon, D. (1989). Evidence for terror management theory: I. The effects of mortality salience on reactions to those who violate or uphold cultural values. Journal of Personality and Social Psychology, 57(4), 681-690. 
Routledge, C., \& Arndt, J. (2007). Self-sacrifice as self-defence: Mortality salience increases efforts to affirm a symbolic immortal self at the expense of the physical self. European Journal of Social Psychology, 38(3), 531-541.

Routledge, C., Arndt, J., \& Sheldon, K. M. (2004). Task engagement after mortality salience: The effects of creativity, conformity and connectedness on worldview defence. European Journal of Social Psychology, 34(4), 477-487.

Routledge, C., Arndt, J., Vess, M., \& Sheldon, K. M. (2008). The life and death of creativity: The effects of mortality salience on self versus social-directed creative expression. Motivation and Emotion, 32(4), 331-338.

Routledge, C., \& Juhl, J. (2012). The creative spark of death: The effects of mortality salience and personal need for structure on creativity. Motivation and Emotion, 34(4), 478-482.

Routledge, C. D., \& Arndt, J. (2009). Creative terror management: Creativity as a facilitator of cultural exploration after mortality salience. Personality and Social Psychology Bulletin, $35(4), 493-505$.

Rutjens, B. T., van Harreveld, F., van der Pligt, J., van Elk, M., \& Pyszczynski, T. (2016). A march to a better world? Religiosity and the existential function of belief in social-moral progress. The International Journal for the Psychology of Religion, 26(1), 1-18.

Ryan, R. M., \& Frederick, C. (1997). On energy, personality, and health: Subjective vitality as a dynamic reflection of well-being. Journal of Personality, 65(3), 529-565.

Schwartz, S. H. (2007). Universalism values and the inclusiveness of our moral universe. Journal of Cross-Cultural Psychology, 38(6), 711-728. 
Schwartz, S. H., Cieciuch, J., Vecchione, M., Davidov, E., Fischer, R., Beierlein, C., . . . Demirutku, K. (2012). Refining the theory of basic individual values. Journal of Personality and Social Psychology, 103(4), 663-688.

Shaheen, K. (2015). Isis fighters destroy ancient artefacts at Mosul museum, The Guardian. Retrieved from http://www.theguardian.com/world/2015/feb/26/isis-fighters-destroyancient-artefacts-mosul-museum-iraq

Shneidman, E. S. (1973). Deaths of a man. New York: Quadrangle.

Silvia, P. J., Kaufman, J. C., \& Pretz, J. E. (2009). Is creativity domain-specific? Latent class models of creative accomplishments and creative self-descriptions. Psychology of Aesthetics, Creativity, and the Arts, 3(3), 139-148.

Silvia, P. J., \& Nusbaum, E. C. (2012). What's your major? College majors as markers of creativity. International Journal of Creativity and Problem Solving, 22(2), 31-43.

Simonton, D. K. (1989). The swan-song phenomenon: Last-works effects for 172 classical composers. Psychology and Aging, 4(1), 42-47.

Sligte, D. J., Nijstad, B. A., \& De Dreu, C. K. W. (2013). Leaving a legacy neutralizes negative effects of death anxiety on creativity. Personality and Social Psychology Bulletin, 39(9), 1152-1163.

Solomon, S., Greenberg, J., \& Pyszczynski, T. (2004). The cultural animal: Twenty years of terror management theory and research. In J. Greenberg, S. L. Koole \& T. Pyszczynski (Eds.), Handbook of experimental existential psychology (pp. 13-34). New York: The Guilford Press.

Sternberg, R. J. (2006). The nature of creativity. Creativity Research Journal, 18(1), 87-98. 
Stevens, J. P. (1984). Outliers and influential data points in regression analysis. Psychological Bulletin, 95(2), 334-344.

Templer, D. I. (1970). The construction and validation of a death anxiety scale. The Journal of General Psychology, 82(2), 165-177.

Thompson, M. M., Naccarato, M. E., Parker, K. C. H., \& Moskowitz, G. B. (2001). The personal need for structure and personal fear of invalidity measures: Historical perspectives, current applications, and future directions. In G. B. Moskowitz (Ed.), Cognitive social psychology: The Princeton symposium on the legacy and future of social cognition (pp. 19-39). Mahwah, NJ: Erlbaum.

Vellante, M., Zucca, G., Preti, A., Sisti, D., Rocchi, M. B. L., Akiskal, K. K., \& Akiskal, H. S. (2011). Creativity and affective temperaments in non-clinical professional artists: an empirical psychometric investigation. Journal of Affective Disorders, 135(1), 28-36.

Victoria and Albert Museum. (2015), from http://www.vam.ac.uk/content/exhibitions/exhibition$\underline{\text { alexander-mcqueen-savage-beauty/about-the-exhibition/ }}$

Vincent, L. C., \& Polman, E. (2016). When being creative frees us to be bad: Linking creativity with moral licensing. In J. W. van Prooijen \& P. A. M. van Lange (Eds.), Cheating, Corruption, and Concealment (pp. 166-184). Cambridge, UK: Cambridge University Press.

Wadaani, M. R. (2015). Teaching for creativity as human development toward self-actualization: The essence of authentic learning and optimal growth for all students. Creative Education, 6, 669-679. 
Wade-Benzoni, K. A., Tost, L. P., Hernandez, M., \& Larrick, R. P. (2012). It's only a matter of time: Death, legacies, and intergenerational decisions. Psychological Science, 23(7), 704709.

Watson, D., \& Clark, L. A. (1992). Affects separable and inseparable: on the hierarchical arrangement of the negative affects. Journal of Personality and Social Psychology, 62(3), 489-505.

Watson, D., Clark, L. A., \& Tellegen, A. (1988). Development and validation of brief measures of positive and negative affect: The PANAS scales. Journal of Personality and Social Psychology, 54, 1063-1070.

Weisberg, R. W. (2011). Frank Lloyd Wright's fallingwater: A case study in inside-the-box creativity. Creativity Research Journal, 23(4), 296-312.

Wisman, A., \& Goldenberg, J. L. (2005). From the grave to the cradle: Evidence that mortality salience engenders a desire for offspring. Journal of Personality and Social Psychology, 89(1), 46-61.

Wisman, A., \& Heflick, N. A. (2016). Hopelessly mortal: The role of mortality salience, immortality and trait self-esteem in personal hope. Cognition and Emotion, 30(5), 868889.

Wojtkowiak, J., \& Rutjens, B. T. (2011). The postself and terror management theory: Reflecting on after death identity buffers existential threat. The International Journal for the Psychology of Religion, 21(2), 137-144.

Xu, H., \& Brucks, M. L. (2011). Are neurotics really more creative? Neuroticism's interaction with mortality salience in determining creative interest. Basic and Applied Social Psychology, 33(1), 88-99. 
Xu, H., Brucks, M. L., \& Guo, L. (2013). Creative consumption after mortality salience: Compared to what, for whom, what tasks? And a time horizon issue. Journal of Research for Consumers(24), 1-5.

Yaakobi, E. (2015). Desire to work as a death anxiety buffer mechanism. Experimental Psychology, 62, 110-122.

Yalom, I. D. (1980). Existential Psychotherapy. New York: Basic Books, Inc., Publishers. 
Table 1. Papers on the relationship between mortality salience and creativity $(N=12)$

\begin{tabular}{|c|c|c|c|c|}
\hline & Creativity task & Dependent variable & Measurement of dependent variable & MS-creativity findings \\
\hline Arndt et al., & Writing a story & Guilt (S1), positive & State Guilt scale of the Guilt & Following MS, creative task participants who received neutral \\
\hline \multirow[t]{8}{*}{2005} & & engagement (S2) & Inventory (Kugler \& Jones, 1992); & personality feedback reported significantly more guilt when \\
\hline & & & positive engagement was comprised & compared to controls. In addition, MS creative task participants \\
\hline & & & of the positive mood scale (Watson \& & showed significantly less guilt when first receiving feedback \\
\hline & & & Clark, 1992), the vitality scale (Ryan & emphasizing their conformity than when receiving neutral feedback \\
\hline & & & $\&$ Frederick, 1997), and the Problem- & (S1); following MS, participants who wrote about goals that others \\
\hline & & & Solving Creativity subscale of the & value reported significantly more positive engagement than \\
\hline & & & Self-Description Questionnaire & participants who wrote about self-value goals (S2). \\
\hline & & & (Marsh \& O'Neill, 1984). & \\
\hline Arndt et al., & Writing a story & Guilt (S1, S2), social & State Guilt scale of the Guilt & Creative task participants reported significantly more guilt following \\
\hline \multirow[t]{3}{*}{1999} & & projection of & Inventory (Kugler \& Jones, 1992), 16 & MS when compared to controls (S1, S2); MS creative-task \\
\hline & & attitudes (S3) & items from the Minnesota Multiphasic & participants exhibited significantly higher social projection when \\
\hline & & & Personality Inventory-2 (Butcher, & compared to all other participants (S3). \\
\hline
\end{tabular}


Dahlstrom, Graham, Tellegen, \&

Kaemmer, 1989).

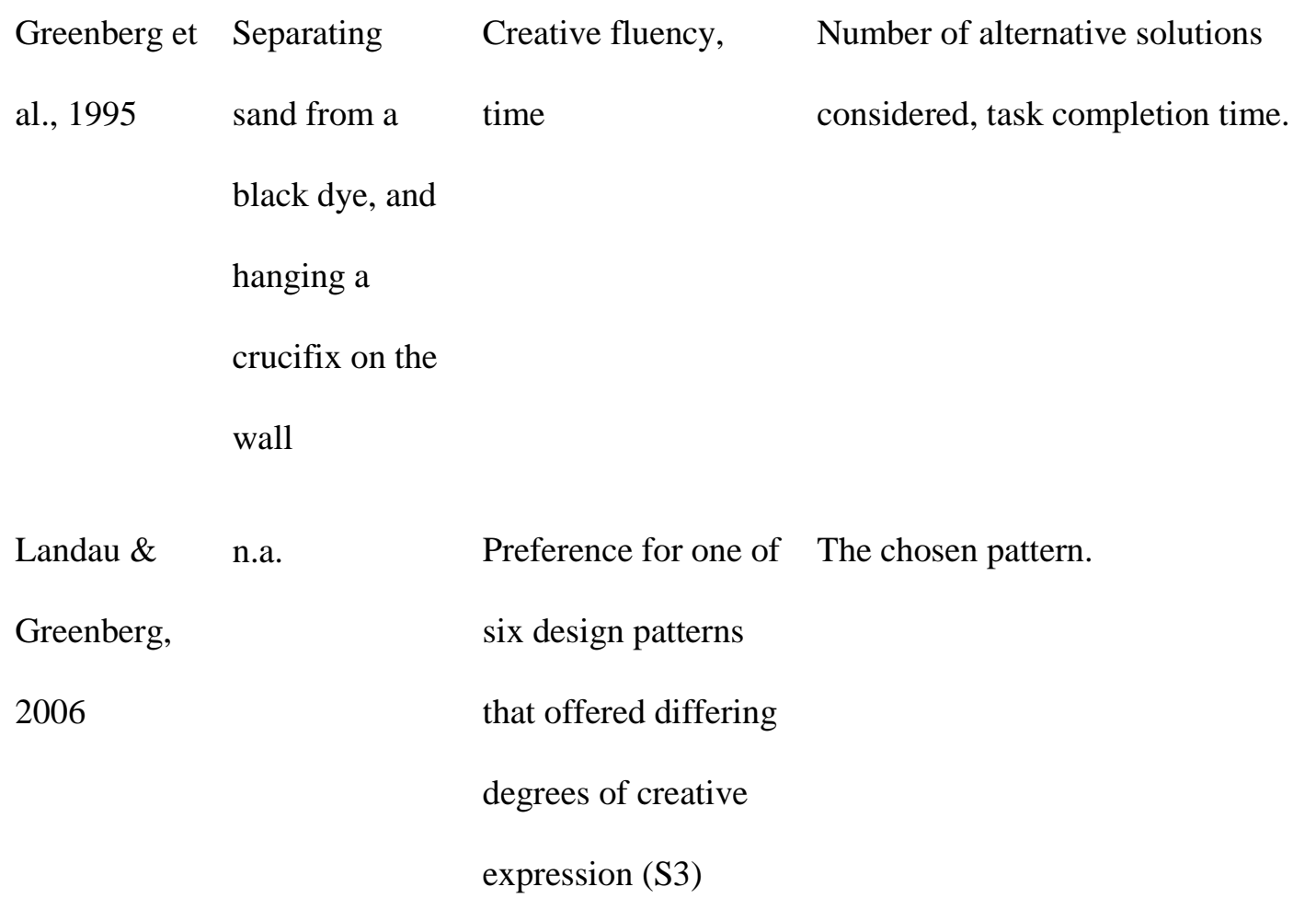

MS participants in the cultural objects-condition took significantly longer to complete the tasks, and considered significantly more alternative solutions in comparison to MS participants in the neutralobjects condition and controls.

Following MS, participants with high self-esteem opted for a highrisk creativity task which allowed greater creative expression, while persons with low self-esteem opted for a low-risk task, which allowed limited creative expression. 


\begin{tabular}{|c|c|c|c|}
\hline Long \& & Generating & Humorousness & Self-assessed and assessed by extern \\
\hline Greenwood, & humorous & & raters. \\
\hline 2013 & $\begin{array}{l}\text { cartoon } \\
\text { captions }\end{array}$ & & \\
\hline $\begin{array}{l}\text { Routledge \& } \\
\text { Juhl, } 2012\end{array}$ & $\begin{array}{l}\text { Creative T- } \\
\text { shirt design }\end{array}$ & Creativity & Assessed by external raters. \\
\hline Routledge \& & Creative T- & General (S1), & Exploration scale (S1) (Green \& \\
\hline Arndt, 2009 & shirt design & $\begin{array}{l}\text { nationalistic (S2), } \\
\text { and religious (S3) } \\
\text { worldview } \\
\text { exploration }\end{array}$ & $\begin{array}{l}\text { Campbell, 2000), rating worldview- } \\
\text { related film descriptions. }\end{array}$ \\
\hline
\end{tabular}

Explicit MS participants rated their cartoons' captions as significantly more humorous captions in comparison to control participants. When the captions were rated by outside rater, the reverse pattern was found. When using subliminal primes, deathprimed participants showed significantly higher levels of creativity in comparison to controls.

In response to mortality reminders, persons with low PNS demonstrated significantly increased creativity while the creativity of persons with high PNS was unaffected.

Participants who engaged in a creative task $(\mathrm{S} 1, \mathrm{~S} 2)$ or read an essay valuing creativity (S3) demonstrated significantly higher levels of worldview exploration following MS, when compared to control participants. 


\begin{tabular}{|c|c|c|c|}
\hline Routledge et & Creative & Creativity & Level of creativity on the rock star \\
\hline al., 2008 & concert & & promotion task as assessed by two \\
\hline & proposal & & independent coders. \\
\hline
\end{tabular}

\section{Routledge et Creative T- Nationalistic Rating an anti-American essay.}

al., $2004 \quad$ shirt design worldview defense

Sligte et al., Naming an Originality, creative Unique responses index (originality),

2013

animal $(\mathrm{S} 1$,

fluency

S2);

brainstorm
Following MS, community-oriented participants were significantly more creative when compared to self-oriented participants; MS

significantly decreased creativity for participants in the self-oriented condition, but not for participants in the community-directed, when compared to control participants.

Following MS, creative task participants showed significantly less worldview defense in comparison to conformity task participants.

MS participants in the legacy condition had significantly higher levels of originality in comparison to those in the non-legacy condition (S1). The same pattern was found when comparing originality and fluency scores in MS participants who were high, but not among those who were low, on individualism (S3). In the socially-valued creativity condition, MS participants were significantly more original under legacy when compared to no legacy. In the social negative valuation condition, MS participants were significantly more fluent under legacy in comparison to no 


\section{$\mathrm{Xu}$ et al.,}

n.a.

2014

\begin{abstract}
$\mathrm{Xu} \&$
\end{abstract}
n.a.

Brucks,
Creative interest, Self-rated momentary interest in

death-words

accessibility

time task

Self-rated momentary interest in specific creative activities, legacy (S2). After performing a creative task, MS participants had higher death thought accessibility under legacy when compared to no legacy (S3).

MS increased creative interest (S1), particularly among those with a pre-existing creative tendency (S2) and in creative activities with a low level of challenge (S3) in comparison to a control condition.

Following MS, persons who wrote about previous creative endeavors showed significantly greater suppression of death-related words in comparison to persons who wrote about past spending experiences (S4). No comparison of these two groups with the control condition was reported, and the control group completed no (MS) comparable task.

Participants with lower levels of neuroticism, but not those with higher levels of neuroticism, had significantly increased creative interest following MS. 

Table 2. Mini meta-analysis of the effect of death awareness on creativity

\begin{tabular}{|c|c|}
\hline dent variabl & Rating method \\
\hline
\end{tabular}

Study

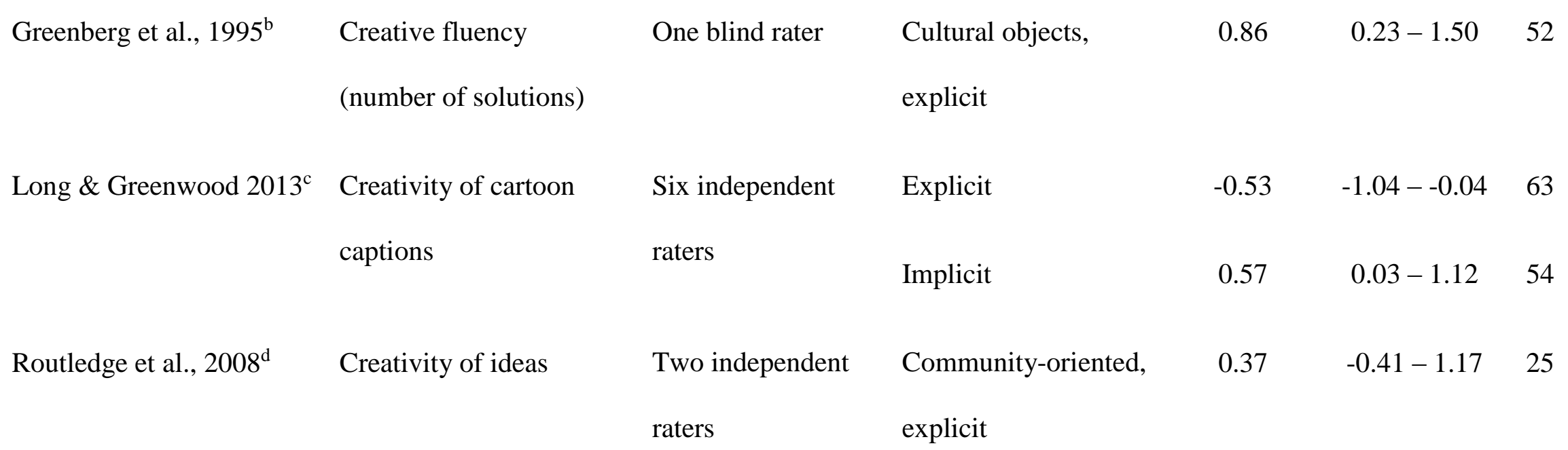

Weighted mean effect size

$0.30-0.36-0.96$

${ }^{\mathrm{a}}$ All samples were US students. ${ }^{\mathrm{b}}$ Effect size was calculated based on the t statistic, $\mathrm{t}(48)=2.77$ and represents a 1 ( $\left.n=14\right)$ vs. $3(n=$ 38) comparison between MS cultural-objects condition and the other three conditions. ${ }^{\mathrm{c}}$ Data was treated as two separate studies given the independency of samples. ${ }^{\mathrm{d}}$ Effect size was calculated based on the F statistic, $\mathrm{F}(1,23)=0.91$. 
Table 3. Descriptive statistics of independent variables $(N=108)$

\begin{tabular}{llrl}
\hline M (SD) & Min - Max & Alpha & Skewness $^{\mathrm{a}} \quad$ Kurtosis $^{\mathrm{b}}$ \\
& & \\
& & \\
& &
\end{tabular}

\begin{tabular}{lccccc}
\cline { 2 - 5 } Creative achievement & $0.94(0.90)$ & $0-4.60$ & n.a. & 1.84 & 3.60 \\
Creative goals & $2.87(1.02)$ & $1-5$ & .79 & -0.12 & -0.86 \\
\hline
\end{tabular}

n.a. = Not applicable

${ }^{\mathrm{a}}$ Skewness Standard Error $=0.23,{ }^{\mathrm{b}}$ Kurtosis Standard Error $=0.46$ 
Table 4. Hierarchical regression predicting death-thought accessibility $(N=108)$

\begin{tabular}{lccc}
\hline & \multicolumn{3}{c}{ Hierarchical model } \\
\cline { 2 - 4 } Step1 & B & SE B & $\beta$ \\
\cline { 2 - 4 } Constant & & & \\
Condition (1= MS) & .25 & .16 & .10 \\
CA & .07 & .28 & .06 \\
CG & .16 & .11 & .13 \\
Step 2 & & & \\
Constant & 2.25 & .16 & \\
Condition (1= MS) & .24 & .23 & .10 \\
CA & .19 & .19 & .15 \\
CG & .30 & .16 & $.26^{\mathrm{a}}$ \\
Condition * CA & -.28 & .25 & -.15 \\
Condition * CG & -.26 & .22 & -.16 \\
CA * CG & -.05 & .11 & -.05
\end{tabular}

Step 3

\begin{tabular}{|c|c|c|c|}
\hline Constant & 2.24 & .15 & \\
\hline Condition $(1=\mathrm{MS})$ & .25 & .22 & .11 \\
\hline $\mathrm{CA}$ & .36 & .20 & $.27^{\mathrm{a}}$ \\
\hline CG & .28 & .16 & $.24^{\mathrm{a}}$ \\
\hline Condition * CA & -.50 & .27 & $-.28^{\mathrm{a}}$ \\
\hline Condition * CG & -.21 & .22 & -.13 \\
\hline $\mathrm{CA} * \mathrm{CG}$ & .24 & .18 & .24 \\
\hline Condition $* \mathrm{CA} * \mathrm{CG}$ & -.45 & .22 & $-.35^{*}$ \\
\hline
\end{tabular}

